\title{
The Relationship of Family Function with Internet Addiction among Girl High School Students in Malard
}

\author{
Azam Habibi ${ }^{1}$ \\ Dr. Parvaneh Danesh²

\section{Dr. Mohammad Javad Zahedi Mazandarani ${ }^{3}$} \\ ${ }^{1}$ MA in Sociology, Payam Noor University of Tehran \\ ${ }^{2}$ Assistant Professor at Payam Noor University of Tehran, \\ ${ }^{3}$ Associate Professor at Payam Noor University of Tehran, \\ azamhabibi5@yahoo.com,p_danesh@pnu.ac.ir, m_zahedi@pnu.ac.ir
}

Doi:10.5901/mjss.2015.v6n4s3p215

\begin{abstract}
The present study aims to investigate the relationship between family function with internet addiction in girl high school students in Malard. This study was a descriptive survey of a correlational type. The statistical population of the present study was all of girl high school students in Malard between 2014 and 2015. 400 individuals of them were selected as the sample based on Cochran formula. 4 out of 19 girl high schools in Malard were chosen using a random-classified method. Then, some students were selected among these schools using a simple-random method. In order to collect required data and information in this study, family assessment device (FAD) standard questionnaire and internet addiction standard questionnaire were used that have been previously confirmed in validity and reliability researches. The results of the present study showed that students' internet addiction increased with enhancement of improper family function. Also, the results of the present study showed that with enhancement of unhealthy problem solving in the family, roles and unhealthy responsibilities in the family, unhealthy affective involvement in the family, and unhealthy emotional response in the family, students' internet addiction increased.
\end{abstract}

Keywords: Family function, Internet addiction, Students

\section{Introduction}

Internet addiction is a new and attractive issue that has been recently considered as a behavior-based addiction. People with internet addiction who spend hours and days in social networks cannot disconnect this connection and are not interested in leaving their computers. While their real life activities and their social communications collapse and they become more dissociable (Yang and Tung, 2004; quoted by Ghaffari and Ahadi, 2006). In this regard, Sanders (2000) reported the decrease in relationship with parents, seclusion from society among intemperate users. He believed that this issue leads to decrease in social support and contact among users and finally causes depression and solitude among them because a person during adolescence needs to share his/her emotions, excitement, doubts, and wishes (quoted by Ghaffari and Ahadi, 2007: 92). Today, the prevalence of internet addiction among adolescents can be discussed as a serious crisis in their individual and social life (Berig, Meridith, 1993; De yong-Jerold, 1987; Medora, Woodward, 1986; Pilao, Perlman, 1982; quoted by Ghasemi and Malek Ahmadi, 2010). The results of studies show that when various habits take a form of addiction affect on different parts of the life badly (Shepherad, 2005). In this regard, researches have shown that internet addiction has harmful effects on the most important responsibilities of students, namely education (Ranjbar et al., 2011). On the other hand, researches show that home is the first location in people life and it must be such that creates the spirit of peace and balance among their members. The existence of a warm, with spirit, and thriving environment in the family is a confident base for their members and guarantees mental health of people (Norouzi, 2003). Attention to the family and attempt for problem solving of this organization can promise a valuable society (Mousavi, Moradi, and Mahdavi Hersini, 2005. Family function is as one of the important indices guaranteeing life quality and mental health of the family and their members and can be as a key factor in creating flexibility and decreasing current and future risks related to unpleasant events and improper conditions (Silborn, Zubrick, De Maio, Shepherad, and Greeffin, 2006). The results of Norouzi's study (2003) report positive effects of behavior style of intimate, responder, and integrated families and negative effects of behavior style of apathetic, opinionated, disordered families on mental health 
of people.

On the other hand, researches have shown that desirability, satisfaction, quality, and optimal function of the family are effective factors on growth, inflorescence, and advancement of family members (Behboudi et al., 2009). Achievement of a healthy society indebted the health of family and healthy family indebted having people with mental health and having desirable relationship with each other. Proper family function can be helpful for its members to be consistent with undesirable conditions and unpleasant life. Disorder in family function results in bewilderment, anxiety, and communicational problems among its members and threatens the health of its members (Ghamari and Khoshnam, 2011). This is a point that also Zadeh Mohammadi and Malek Khosravi (2006) greatly emphasized it. They believed that when family patterns are helpful to achieve goals, family is efficient from aspect of function. When family patterns are not useful to achieve goals, interactions are occurred with stress and sick behaviors and the family will be inefficient. The role of the family and its function in girl students' internet addiction have been less considered, therefore, this research aims to investigate the role of the family in internet addiction among adolescent girl students in high schools in Malard. The reason for selecting girl students is that the results of studies show that this phenomenon among girl students has a more prevalence than that among boy students (Shepherad, 2005). This research aims to determine the relationship between family function and internet addiction among students. According to opinions of school counselors and experts in Malard about stating five main problems among high school students of this city which have been stated in order of preference, the results of their opinions showed that intemperate use of internet and computer games are a part of main problems of students in this city and is placed in the first five preferences. The most important reasons for selecting the subject of this study are as follows: allowed immigration to this city, diversity of the culture, low level of life among a majority of people, cultural poverty, role of family in filling these gaps, and also lack of similar studies in this field in Malard.

\section{Research hypotheses}

\subsection{Main hypothesis}

Family function has a relationship with internet addiction among girl high school students in Malard.

\subsection{Secondary hypothesis}

1. Problem solving in the family has a relationship with internet addiction among girl high school students in Malard.

2. Relations in the family have a relationship with internet addiction among girl high school students in Malard.

3. Responsibilities in the family have a relationship with internet addiction among girl high school students in Malard.

4. Affective involvement has a relationship with internet addiction among girl high school students in Malard.

5. Emotional response in the family has a relationship with internet addiction among girl high school students in Malard.

6. Behavior control in the family has a relationship with internet addiction among girl high school students in Malard.

7. Family function has a relationship with internet addiction among girl high school students in Malard.

\section{Research Background}

Yan et al. (2014) in a research investigated the relationship of stressful events in the life, personality traits, perception, and family function with internet addiction among students. They reported in their research that internet addiction recently has been discussed as an important issue affecting on social and mental health of adolescents. Therefore, the analysis of effective factors on internet addiction is very important for perception of increased internet addiction among adolescents. For investigation of relationship among recent stressful events, they studied personality traits, family perception function, and internet addiction of 892 students. The results showed that people with internet addiction in comparison with nonaddicted ones had a lower family function, a lower extroversion, and more stressful events in their life. People who had a slighter internet addiction had a higher mental health and more consistency with problems. Also, the results showed that there is a positive relationship between stress during life and internet addiction.

Senormancie et al. (2014: 203) in a research investigated the relationship of family function in patients with internet addiction. They stated in their research that despite the some advantages of use of internet in people life, some users 
due to excessive use of it encounter with some problems due to poor control during use of internet. Few researches have been done about the relationship of attachment styles and family function with internet addiction. In their research for the purpose of investigating the relationship of attachment styles and family function with internet addiction, they selected 30 men who had confessed to their internet addiction and had referred to psychology clinic, as sample. Also, 30 healthy men who are identical in terms of socio-demographic characteristics are entered into the study as control group. The results showed that patients with internet addiction have a higher depression and anxiety in comparison with control group. Also, it has been determined that people with internet addiction did not have satisfaction from their family function. Also, results showed that there is a significant relationship among components of emotional response, problem solving, behavior control, roles, and total family function with internet addiction. Li et al. (2014) in a research investigated the effect of family factors on internet addiction among Chinese adolescents. They reported in their research that internet addiction among Chinese adolescents has had a growing trend. The results of this research showed that adolescents with internet addiction in comparison with non-addicted ones had families that had not been organized and had a lower solidarity and their parents had more involvement with each other and parents greatly used punishment. Also, they stated in this research that more probably adolescents with internet addiction were from families that their parents were divorced and the child lived with one of parent. Gunuc and Dogan (2013) in a research investigated the relationship of internet addiction with social support and family activities among Turkish adolescents. The aim of their research was to investigate the relationships of internet addiction with social understood support and parents' activities among adolescents. They studied 166 adolescents who had referred to psychological center. The age range was from 12 to 18 years with an average of 15.5 years old. The results showed that there is a negative relationship between understood social support and internet addiction. Also, findings showed that adolescents who spend more time with their mothers have a higher understood social support and consequently, the internet addiction will be lower among them.

\section{Research Theoretical Framework}

The theoretical framework of the present research is based on McMaster theory in the field of family function and Young theory in the field of internet addiction. Many studies have been performed in the field of investigating the psychometric indices of McMaster scale outside of the country. These studies included of McMaster approach to the family, theory, assessment, treatment and research (Miller et al. 2000); investigating the mental indices of Master's family assessment device in nonclinical, medical, and psychiatric samples (Kabakouf, Miller, Bishop and Epstein, and Kitz 1990); McMaster's clinical family assessment device as interview questionnaire for people with brain damages (Barney and Marks 2005); the measurement of cultural sensitivities of McMaster's tool (Mors 1990); functional analysis of McMaster's family assessment device (Ridenour et al. 1999) and investigating validity of subscales of McMaster's assessment device (Byles et al. 1988). In Iran, this device has been normalized by ZadehMohammadi and Malek Khosravi with a total Cronbach alpha of 0.94 for all scales (ZadehMohammadi and Malek Khosravi , 2006). McMaster's scale as one of the most common questionnaires is used in the other countries by family counselors in various research dimensions and family function diagnoses (Miller et al. 2000, quoted by Yousefi 2012). Also, this approach (McMaster's approach) has been used in research hypotheses and theoretical framework of the present research. Also, internet addiction is a term that was firstly used by Young in 1996 and was considered by psychologists, psychiatrists, researchers, therapists, scientists, and specially internet users (Omidvar and Saremi .2002). Young based on moderated criterion (DSM-IV, 1995) received that internet addicted people averagely used internet 38 hours per week, while non-addicted ones only used internet 8 hours per week. Young believes that there is not a certain cutting line separating addicted and non-addicted people. Furthermore, internet addiction is not only determined by use hours. Some people may show the symptom of internet addiction with 20 hours per week, while some other ones who may spend more than 30 hours per week do not show these symptoms (Omidvar and Saremi, 2002). In this research, Young's view is used to assess internet addiction among students.

\section{Method}

This study was a descriptive survey of a correlational type. The statistical population of the present study was all of girl high school students in Malard. This statistics was obtained from Malard Educational and Training. The number of students between 2014 and 2015 was 6322 that 400 out of them were selected as the sample based on Cochran formula. 4 out of 19 girl high schools in Malard were chosen using a random-classified method. Then, among these schools, students were studied using a simple-random method. In order to collect required data and information in this study, family assessment device (FAD) standard questionnaire and Young's internet addiction standard test were used. 


\subsection{Family assessment device (FAD) questionnaire}

This questionnaire has 60 questions and has been developed by Epstein, Bishop, and Baldion in 1983 for assessing family function based on McMaster's pattern. Zadeh Mohammadi and Malek Khosravi (2006) reported the reliability factors of 0.71 for total questionnaire, 0.722 for subscales of problem solving, 0.70 for family communications, 0.71 for roles and responsibilities in the family, 0.736 for affective involvement, 0.66 for behavior control, and 0.71 for emotional response. Since standard questionnaire is used there is no need to investigate the validity and reliability of the questionnaire. This questionnaire includes of 6 dimensions (function, problem solving, communication, roles, affective involvement, behavior control, and emotional response) and the total score of the questionnaire shows the family function. A higher score in this questionnaire indicates unhealthier family function. All of responses are coded from 1 to 5. The score of each question will be between 1to 5. The questions of each dimension are summed and indicate family function in that dimension. A higher score in this questionnaire shows unhealthier family function in related dimension.

\subsection{Young's internet addiction test (IAT) with 20 questions}

Internet addiction test is one of the most common tests related to internet addiction assessment that was invented by Kimberley Young. A higher score in the IAT means more internet addiction. The completion of 20-question internet addiction questionnaire indicates the addiction of the student to internet. The scores are summed. If the summation of scores becomes from 20 to 49, the students is an ordinary internet user. If the summation of scores becomes from 50 to 79 , the students is in a risk of internet addiction and he/she must be watchful. If the score becomes from 80 to 100, it shows internet addiction of the student. The Persian release of this questionnaire has been previously used in Iran. Using Cronbach alpha, Nastizayee and Ghasemzadeh reported the reliability of 0.81 and 0.88 , respectively (Quoted by Bahri et al., 2011). In this research, the students who obtained scores from 80 to 100 were considered as internet addicted persons. Tamannayeefar, Sedighi Arfaee, and Gandomi (2012) and Khanjani and Akbari (2011) reported a high reliability of internet addiction questionnaire. Since standard questionnaire is used there is no need to investigate the validity and reliability of the questionnaire. Information analysis in this research is done using both descriptive and inferential methods. In the descriptive analysis of data and information, average descriptive statistics, standard deviation, frequency, and percentage were used. In the inferential section, according to research hypotheses, Pearson correlation test and SPSS software were used.

\section{Findings}

From a total of 400 students, $27 \%$ of responders were in third grade, $25 \%$ was in fourth grade, $24 \%$ of them were in first grade, and $24 \%$ was in second grade. $32 \%$ of responders were diploma, $30 \%$ of them were under diploma, $17 \%$ of them were Associate, $10 \%$ was illiterate, $9 \%$ was bachelor, and $1 \%$ was Master of Science or art.

\subsection{Description of research variables in terms of students' internet addiction}

Table 1 shows the frequency distribution of responders in terms of students' internet addiction. According data of this table, $75 \%$ of responders are ordinary internet user, $14 \%$ were as users at the risk of internet addiction, and $10 \%$ of responders have internet addiction.

Table 1 - The distribution of responders in terms of students' internet addiction

\begin{tabular}{|l|c|c|c|c|}
\hline Internet addiction amount & Frequency & Percent & Valid percent & Cumulative percent \\
\hline Ordinary internet user & 302 & 75.5 & 75.5 & 75.5 \\
\hline At the risk of internet addiction & 56 & 14.0 & 14.0 & 89.5 \\
\hline Internet addiction & 42 & 10.5 & 10.5 & 100.0 \\
\hline Total & 400 & 100.0 & 100.0 & \\
\hline
\end{tabular}

Table 2 shows descriptive statistics of internet addiction variable. According to this table, the average of internet addiction of responders, its minimum, its maximum, and standard deviation were $55,18,98$, and 14 , respectively. 
Table 2 - Descriptive statistics of internet addiction variable

\begin{tabular}{|l|c|c|c|c|c|}
\hline & Number & Minimum & Maximum & Average & Standard deviation \\
\hline Internet addiction amount & 400 & 18 & 98 & 55.36 & 14.750 \\
\hline
\end{tabular}

\subsection{Descriptive statistics of family function indices}

Table 3 shows descriptive statistics of total family function and its indices. According to instruction of the questionnaire, the higher score in the questionnaire indicates unhealthier total family function and related dimensions. According to data of this table, the average unhealthy family functions of responders, its minimum, its maximum, and its standard deviation were $172,140,196$, and 13 , respectively. About unhealthy family function indices, the highest averages are related to roles and responsibilities 34 , behavior control in the family 25 , communications in the family 24 , affective involvement in the family 21 , emotional response 18 , and problem solving in the family 15.

Table 3 - Descriptive statistics of total unhealthy family function and its indices

\begin{tabular}{|l|c|c|c|c|c|}
\hline & Number & Minimum & Maximum & Average & Standard deviation \\
\hline Total family function & 400 & 140 & 196 & 171.96 & 13.426 \\
\hline Problem solving in the family & 400 & 8 & 22 & 15.16 & 3.430 \\
\hline communications in the family & 400 & 18 & 30 & 24.08 & 3.338 \\
\hline roles and responsibilities in the family & 400 & 23 & 42 & 33.80 & 5.050 \\
\hline affective involvement in the family & 400 & 12 & 29 & 20.96 & 4.410 \\
\hline behavior control in the family & 400 & 18 & 34 & 25.48 & 3.895 \\
\hline Emotional response in the family & 400 & 12 & 23 & 17.88 & 2.458 \\
\hline
\end{tabular}

\subsection{Inferential statistics}

Table 4 is related to Pearson correlation test between total family function and its dimensions with students' internet addiction. According to questionnaire instruction, a higher score in this questionnaire shows unhealthier family function. Thus, the results showed that the significance level is lower than 0.05 and therefore initial hypothesis is rejected in level of 0.05 . Therefore, total unhealthy family function has a positive significant relationship with internet addiction among girl high school students in Malard. It means with enhancement of unhealthy family function internet addiction has been increased among students. According to questionnaire instruction, a higher score in problem solving shows unhealthier problem solving in the family and in accordance with significance level lower than 0.05 , initial hypothesis is rejected in level of 0.05 and consequently, unhealthy problem solving in the family has a positive significant relationship with internet addiction among girl high school students in Malard. It means with enhancement of unhealthy problem solving in the family internet addiction has been increased among students. According to questionnaire instruction, a higher score in family communications shows unhealthier family communications. In accordance with significance level more than 0.05 , initial hypothesis is not rejected in level of 0.05 and consequently, unhealthy communications in the family has not a significant relationship with internet addiction among girl high school students in Malard. According to questionnaire instruction, a higher score in family responsibilities shows unhealthier function of family responsibilities. In accordance with significance level lower than 0.05 , initial hypothesis is rejected in level of 0.05 and consequently, unhealthy communications and roles in the family has a positive significant relationship with internet addiction among girl high school students in Malard. It means with enhancement of unhealthy roles and responsibilities in the family, internet addiction has been increased among students. According to questionnaire instruction, a higher score in affective involvement shows unhealthier function of affective involvement in the family. In accordance with significance level lower than 0.05 , initial hypothesis is rejected in level of 0.05 and consequently, unhealthy affective involvement in the family has a positive significant relationship with internet addiction among girl high school students in Malard. It means with enhancement of unhealthy affective involvement in the family, internet addiction has been increased among students. According to questionnaire instruction, a higher score in behavior control in the family shows unhealthier in behavior control in the family. In accordance with significance level more than 0.05 , initial hypothesis is rejected in level of 0.05 and consequently, behavior control in the family has not a significant relationship with internet addiction among girl high school students in Malard. According to questionnaire instruction, a higher score in emotional response in the family shows unhealthier in emotional response in the family. In accordance with significance level of lower than 0.05 , initial 
hypothesis is rejected in level of 0.05 and consequently, emotional response in the family has a positive significant relationship with internet addiction among girl high school students in Malard.

Table 4 - Investigating the relationship of internet addiction with total family function

\begin{tabular}{|l|l|c|}
\hline \multicolumn{2}{|c|}{} & Internet addiction \\
\hline \multirow{4}{*}{ Total family function } & Correlation factor & 0.362 \\
\cline { 2 - 3 } & Significance level & 0.000 \\
\cline { 2 - 3 } & Number & 400 \\
\hline \multirow{5}{*}{ Problem solving in the family } & Correlation factor & 0.290 \\
\cline { 2 - 3 } & Significance level & 0.000 \\
\cline { 2 - 3 } & Number & 400 \\
\hline \multirow{5}{*}{ Communication in the family } & Correlation factor & 0.043 \\
\cline { 2 - 3 } & Significance level & 0.387 \\
\cline { 2 - 3 } & Number & 400 \\
\hline \multirow{5}{*}{ Affective involvement in the family } & Correlation factor & 0.237 \\
\cline { 2 - 3 } & Significance level & 0.000 \\
\cline { 2 - 3 } & Number & 400 \\
\hline \multirow{3}{*}{ Behavior control in the family } & Correlation factor & 0.235 \\
\cline { 2 - 3 } & Significance level & 0.000 \\
\cline { 2 - 3 } & Number & 400 \\
\hline \multirow{3}{*}{ Emotional response in the family } & Correlation factor & 0.048 \\
\cline { 2 - 3 } & Significance level & 0.339 \\
\cline { 2 - 3 } & Number & 400 \\
\hline & Correlation factor & 0.145 \\
\cline { 2 - 3 } & Significance level & 0.004 \\
\cline { 2 - 3 } & Number & 400 \\
\hline & & \\
\hline
\end{tabular}

\section{Discussion and Conclusion}

The results of the current research show that with enhancement of unhealthy family function, internet addiction increases. Also, the results of the present research show that with enhancement of unhealthy family function, unhealthy problem solving in the families, unhealthy roles and responsibilities, unhealthy affective involvement, and unhealthy emotional response in the family, internet addiction increases among students. Ian et al. (2014) also reported that unhealthy family function in the family is related with internet addiction among children that this finding is consistent with the results of the present research. Ian et al. (2014) reported that more stress people endure during life, more probability exists for internet addiction. The mechanism of this effect is such that the family can be the base of the consistency of the individual with environment and decreased stress thus, it can be expected that the better family function is accompanied by decreased internet addiction among children. Senormancie et al. (2014) in a research also reported that people with internet addiction have not satisfaction from their family function. The results of their research showed that there is a significant relationship among components of emotional response problem solving, behavior control, roles and total family function with internet addiction. These findings are also consistent with the findings of the present research. Li et al. (2014) reported that people with internet addiction have families that had not been recognized and had lower solidarity and their parents had more involvement with each other and also their parents greatly used punishment with respect to warm and support methods. This finding is also in direction of the present research results. Gunuc and Dogan (2013) reported that there is a negative relationship between understood social support and internet addiction. Substantially, in this area the families that have better function, spend more time with their children and it is natural that children in these families understand more social support through this way. Li and Zhang (2004) also reported that in families with internet addiction there is more intervention, extreme punishment, and willing to more disobeying and this is resulted from unhealthy family function that this finding is consistent with the results of the present research. About effective mechanism of internet, researches show that internet addiction results in damages to the person because of ignoring economic, social, and physical responsibilities (quoted by wizshepherad, 2005). Sanders et al. (2000) also reported that decreased communication with parents, seclusion from society among extreme internet users and they believed that this point leads to decreased social support and social contact and finally will result in depression and solitude among them (quoted by Ghasemi and Malek Ahmadi, 2010). The results of Lio and Kuo (2007) also showed that the relationship of 
parents-children has a positive relation with the quality of interpersonal relations of participants in the research. Furthermore, the results of the research showed that interpersonal relationships and child-parents relation are as predictor of internet addiction. The results of this research emphasize the importance of family environment on intensification to internet addiction. Thus, family environment must be considered in designing therapeutic programs. At the end, it is stated that special approaches must be provided for people with severe internet addiction and guide them to leave the addiction and correct use. Preventing people who use internet normally from internet addiction is one the most important priorities and non-addicted ones must be familiarized with correct use, outcomes and signs of abuse. Meanwhile, it is proposed that a similar research can be done in the other cities, because the age of internet users has been decreased during recent years and it seems necessary preventive practices must be considered by experts and authorities according to exact internet users.

\section{References}

Bahri Binabaj N., Sedegh Moghaddam L., Khodadoust L., Mohammadzadeh J., Banafsheh A., (2011), The status of internet addiction and its relation with general health of students of Gonabad Medical Sciences, New Cares, 8(31) 166-173.

Behboudi M., Hashemian K., Sharifi H.P., Navvabinejad Sh., (2009), the prediction of family function based on couple's personality characteristics, Thought and Behavior, 3(11) 55-66.

Berge J. M. , Wall, M. , Larson, N., , Loth, Katie A. Neumark-Sztainer, D. (2012). Family Functioning: Associations With Weight Status, Eating Behaviors, and Physical Activity in Adolescents. Journal of Adolescent Health. Volume 52, Issue 3 , P.P.:351-357

Ghaffari M.,Ahadi H., (2007), the effect of education of excitement self-awareness and impulse control on decreasing social seclusion and forced internet use, psychological studies, 3(3) pp. 91-107.

Ghamari, Khoshnam A.H., (2011), investigating the relation of family function and life quality among students, Scientific-Research Journal of family research, year 7, No. 27, pp. 343-354.

Ghasemi V., Malek Ahmadi H., (2010), determining internet addiction among café net users in Shahinshahr, Journal of communicational researches (Research and Assessment), year 17, №. 4, pp. 51-77.

Ghasemzadeh L., Shahraray M., Moradi A.R., (2007), investigating the rate of prevalence of internet addiction among girls and comparison of addicted and non-addicted girls to internet in variables of solitude, self-esteem, and social skills, contemporary psychology, 2(1) pp. 32-38.

Khanjani Z., Akbari S., (2011), the relation of personality characteristics of adolescents and their internet addiction, new findings in psychology, 6th year, №. 19, pp. 113-127.

Khosravi Z., Alizadeh Sahraee A.H., (2011), the relation of internet addiction with family function and mental health in students, Journal of educative psychological studies, 8th year, No. 14, pp. 59-80.

Li,T, \& Zhang,L.(2004). How College Students' Internet Addiction are Related to Parental Rearing Patterns. Psychological Science (China), 27(3), 662-663.

Lio .c.y.,\& Kuo,F.y.(2007). A study of internet addiction through the lense of the interpersonal theory.cyberpsychology \& behavior,10(6),799-804.

Ling-yan,L.,Deng-HUA,\& Ran,T.(2007).Family function of adolescents with excessive internet usage.chineese mental health journal,21(12),837-840.

Miller, I. W., McDermut, W., Coop Gordon, K., Keitner, G. I., Ryan, C. E., \& Norman, W. (2002). Personality and family functioning in families of depressed patients. Journal of Abnormal Psychology, 109(3), 539-45.

Mousavi R., Moradi A.R., Mahdavi Hersini S.A., (2005), investigating the effectiveness of structural family therapy on family function improvement and tailoring matrimony satisfaction in family with separation disorder, Journal of family research, 1(4), pp. 321-335.

Norouzi V., (2003), the effect of family behavior styles on mental status of students and on their attitude toward human relations in schools, Journal of educative innovations, year 2, No. 6, pp. 31-54.

Park, s.K.Jae, ,Kim,j.y \& Cho,C.B.(2008). Prevalence of internet addiction and correlations with family factors among South Korean adolescents.Adolescence, 43(172), 895-909.

Park J.E., Park K., (2001), Medical textbook of prevention and society (general health care), first section, Vol. 2, Translated by Hossein Shojaee Tehrani and Hossein Malek Afzali. Tehran, Samat, 4th publish, pp. 26-42.

Omidvar A.A, Saremi A.A, (2002), internet addiction: description, etiology, prevention, treatment and scales of assessment of internet addiction disorder, counseling center and Pardis psychological services, Mashhad publications: Practice.

Ranjbar, Darvizeh Z., Naraghizadeh A., (2011), the comparison of rate and type of use of internet related to mental health and educational function of students in Tehran, psychological studies, 7(2) pp. 11-35.

Rio M., (2003), motivation and excitement, translated by Seyyed Yahya Mohammadi, Tehran: Nashr-e-Virayesh Institute.

Selim Gunuc , Ayten Dogan (2013), The relationships between Turkish adolescents' Internet addiction their perceived social support and family activities, Computers in Human Behavior 29 , 2197-2207.

Şenormancıemail address Ömer, Güliz Şenormancı, Oya Güçlü, Ramazan Konkan(2014), Attachment and family functioning in patients with Internet addiction, Volume 36, Issue 2, Pages 203-207.

Silborn, S., Zubrick, S., De Maio, J., Shepherad, C., \& Greeffin, J. (2006). The western Australian Aboriginal child health survey: Strengthening the capacity of Aboriginal children, families and communities. Perthicurtin University of technology and 
telethon institute for child health research [On-line]. Available: www.childhealthre-search.com.au/waachs/publications.

Sunwoo K, Rando K. (2002). A study of Internet addiction . Journal of Korean Home Economics Association, English Edition; 3: 1-19.

Tamannayeefar M., Sedighi Arfaee F., Gandoumi Z., (2012), the relation between internet addiction with personality characteristics of high school students, Zahedan Medical Sciences research (East Physician), 14(1) 67-71.

Wansen Yan ,Yonghui Li and Nan Sui.(2014). The Relationship between Recent Stressful Life Events, Personality Traits, Perceived Family Functioning and Internet Addiction among College Students, Issue Stress and Health,Volume 30, Issue 1, p.p. 3-11.

Wen Li, Eric L. Garland, Matthew O. Howard.(2014), Family factors in Internet addiction among Chinese youth: A review of English- and Chinese-language studies, Computers in Human Behavior 31, p.p.: 393-411.

Yazeshfar F., (2005), investigating the internet addiction among café net users in Lar, principles of mental health, 7(25\&26), pp. 27-33.

Yousefi N., (2012), Psychotherapy and family counseling, 4th publish, Porsesh Publication, pp. 123-134.

Zadehmohammadi A., Khosravi M., Ghaffar M., (2006), elementary investigation of psychological characteristics and validation of family function scale, Journal of family research, 5 pp. 69-89. 